\title{
Selecting Materials for Environmental-Friendly Buildings: The Need for Improved Environmental Impact Data
}

\author{
Nachawit, T. ${ }^{1}$
}

\begin{abstract}
Buildings of the future need to be more environmental-friendly. Selecting environmentally-benign materials in design stage would partly help achieving such goal. Examination of existing environmental impact data of building materials reveals that the data differ greatly from one source to another. Comparisons of environmental impact values of selected materials are presented. The sources that give rise to data variation are identified and discussed. The applicability of existing data is assessed from the designers' perspective. Limitations of current practice in data acquisition and presentation are also discussed. It is concluded that existing environmental impact data of building materials are inconsistent and perplexing to designers. An alternative approach to data acquisition and presentation is to break the life cycle of building materials into several phases and to calculate the total impact value as the sum of the impacts of all phases. This would make the determination of the full life cycle value feasible and increase external validity of research results.
\end{abstract}

Keywords: Building material, environmental performance, LCA data, selecting material.

\section{Introduction}

Building designers, and indeed designers in other fields, could play a pivotal role in mitigating global warming, the most challenging environmental problem for the world today. Proper data and information must be available, however, in order for the designers to do the job successfully. This paper examines existing environmental impact data for building materials and demonstrates that improvements are needed before the data can be used by designers. An alternative approach to data acquisition and presentation so that they are more designer-friendly is therefore necessary and is suggested.

Buildings contribute significantly to climate change and other environmental impacts. Buildings consume energy and materials, and generate various kinds of pollutions throughout their life cycles; construction, use, and demolition. Designs of buildings have great influences on the types and degree of impacts to the environment [1].

\footnotetext{
${ }^{1}$ Industrial Management and Technology, School of Science and Technology, Bansomdejchaopraya Rajabhat University, Bangkok 10600, THAILAND.

Email: nachawit@gmail.com, +6624737000,+6624725714

Note: Discussion is expected before June, $1^{\text {st }} 2012$, and will be published in the "Civil Engineering Dimension" volume 14, number 2, September 2012.
}

Received 27 August 2011; revised 19 December 2011; accepted 27 December 2011.
Designs would, for instance, dictate the types and forms of construction materials, methods of construction, and energy requirement in the use phase. All of these, in turn, influence environmental consequences. Environmental-friendly building designs could therefore lead to substantial reduction in such impacts if done right [1, 2]. With increasingly deteriorating environmental problems, it is likely that most buildings of the future are designed in such a way that they are ever friendlier to the environment.

Materials selection is a critical stage in building design that would partly determine the degree of environmental friendliness of buildings [3-7]. Production of construction materials depletes natural resources, consumes energy, and generates all kinds of pollutions. Transportation of these materials from production plants to construction sites requires energy. Among the various applications of existing materials, the volume used for buildings is perhaps the greatest of all. Building materials therefore generate tremendous amount of impacts to the environment. Selecting a particular material means selecting the degree of impacts, and proper materials selection could considerably minimize the degree of 'embedded' environmental impacts of buildings.

Practicing architects and engineers are well aware of environmental problems and are more than willing to improve environmental friendliness of their designs in any ways possible. A survey of practicing Thai architects, for example, revealed that more than $80 \%$ were enthusiastic about environmental- 
friendly building designs [8]. As far as selecting building materials are concerned, these practitioners face an uphill task. There are several problems and obstacles including lack of appropriate information and tools for selecting environmental-friendly materials, time and cost constraints and so on [9-14]. Availability of relevant and accurate information and userfriendly tools would certainly of great assistance to architects and engineers in their efforts to contribute to environmental well-being of the planet [15].

Materials selection is indeed a complex process $[16,17]$. Designers have to wrestle with several design requirements, oftentimes conflicting, to reach final decisions. Numerous materials selection models have been developed in recent years [16,18-20]. Essentially a set of selection criteria, derived from design requirement, are established. Candidate materials are evaluated against such criteria. Those with the highest 'scores' are selected. In most cases, environmental performance criteria are not included in the selection models although environmental impacts considerations are taken into account in the more recent ones. In actual practice, however, selections of materials are still based, in most cases, on intuition, experience, and familiarity with the materials to be selected [21-23]. Environmental considerations are rarely the key concern. This is due partly to the familiarity with the time-honored methods for selecting materials and partly to the lack of relevant data on environmental impacts of materials [24,25]. The former problem is relatively easy to tackle, perhaps through education and/or regulatory measures. The latter is impossible to solve, unless reliable data are available.

There are, in fact, many studies that aim to determine environmental impact values of various building materials in the literature. Quick scanning of the data reveals that the impact values of the same materials from various sources differ considerably. This poses great difficulty for practicing architects and engineers in selecting materials as one does not know which data are the rights or reliable ones. Environmental impact consideration is consequently often neglected in selecting building materials in practice which is a great pity.

Life cycle assessment (LCA) methodology is widely accepted as the most accurate methodology for assessing environmental impacts of materials [26, 27]. The fact that total environmental impacts of a material is the sum of the impacts of individual stages throughout its life cycle makes it rather difficult to quantitatively determine the impact values in practice as there are numerous variables involved. In reality one could, in most cases, assess the impacts resulting from parts of the life cycle of materials. However, only when the whole life cycle is considered do the impact data truly reflect the actual impacts [28-30]. This may be one of the reasons responsible for the variability in and the dearth of reliable environmental impact data available to practicing architects and engineers.

The objective of this work is to examine and analyse the nature of environmental impact data of building materials exist in the literature and assess the 'applicability' or 'user-friendliness' of the data from the designers' perspective. The ultimate goal is to find suitable methods for data acquisition and presentation so that the data are both reliable (i.e. representing actual impacts in specific applications) and user-friendly. Being user-friendly is very important if the hard-earned data from relevant research work are to be extensively used in practice, thus making the real contribution towards reducing environmental impacts of building materials, bearing in mind the nature of design work and the non-specialist nature of designers.

\section{Methodology}

Existing data on environmental impacts of building materials from various sources were collected and analyzed. The sources include relevant journal articles, books and handbooks of building materials, selected databases, and those from our own research. Different ways of presenting impact values were noted. Impact values of the same materials from different sources were compared together with the methods by which the data were obtained. Where possible, details of respective experimental procedures, assessment methodologies, and other relevant information that led to the impact values were carefully examined.

Environmental impacts data of ceramic tiles are used as the focus of this study. The reason being that the authors have conducted a study on environmental impacts of ceramic tiles in Thailand and that the data for ceramic tiles are readily accessible in the literature, thus facilitating detailed analysis and comparisons.

In-depth interviews with practicing architects in Thailand were conducted. The issues covered in the interviews include; awareness of environmental problems, environmental-friendliness considerations in building designs, materials selection methods, obstacles in improving current design practice, and the use of existing tools for materials selection and building designs in general. The interviews were semi-structured and were conducted face-to-face. The transcripts of the interviews were systematically analysed to gain some insights into current situation 
regarding environmental-friendly designs of buildings in Thailand.

The results of the analysis of existing environmental impact data and those from the interviews were then examined from the designers' perspectives. The 'ease of use' of existing data, as far as designers are concerned, was then assessed and relevant problems and difficulties identified. Possibilities for improvements in methods for data acquisition and presentation so that they are more reliable and more user-friendly are then proposed.

\section{Results and Discussion}

\section{Presentation of Data}

Examining the environmental impact data of building materials from existing literature including documents, textbooks, research reports and databases disseminated on websites, it is found that the data are presented in a variety of units. Impact categories and functional units reported in different sources are also different. Examples of the different units used for some impact categories are shown in Table 1.

Table 1. Examples of the Environmental Impact Data Units of Various Impact Categories

\begin{tabular}{llc}
\hline $\begin{array}{c}\text { Environmental impact } \\
\text { category }\end{array}$ & Impact Data Unit & $\begin{array}{c}\text { Functional } \\
\text { Unit }\end{array}$ \\
\hline Global warming & $\mathrm{kg}(\mathrm{g}) \mathrm{CO}_{2} \mathrm{eq}$ & $\mathrm{Mg}$ \\
& $\mathrm{Pt}$ & $\mathrm{kg}$ \\
& & $1 \mathrm{~m}^{2}$ \\
& & $1 \mathrm{f}^{2}$ \\
\hline Eutrophication & $\mathrm{kg}(\mathrm{g}) \mathrm{NO}_{3} \mathrm{eq}$ & $\mathrm{Mg}$ \\
& $\mathrm{kg}(\mathrm{g}) \mathrm{PO}_{4} \mathrm{eq}$ & $\mathrm{kg}$ \\
& $\mathrm{Pt}$ & $1 \mathrm{~m}^{2}$ \\
\hline Acidification & $\mathrm{mg} \mathrm{H}+\mathrm{eq}$ & $\mathrm{Mg}$ \\
& $\mathrm{kg}(\mathrm{g}) \mathrm{SO}_{2} \mathrm{eq}$ & $\mathrm{kg}$ \\
& $\mathrm{Pt}$ & $1 \mathrm{~m}^{2}$ \\
& & $1 \mathrm{f}^{2}$ \\
\hline Ozone depletion & $\mathrm{kg}(\mathrm{g}) \mathrm{CFC}^{2} 11 \mathrm{eq}$ & $\mathrm{Mg}^{2}$ \\
& $\mathrm{Pt}$ & $\mathrm{kg}$ \\
& & $1 \mathrm{~m}^{2}$ \\
& & $1 \mathrm{f}^{2}$ \\
\hline
\end{tabular}

If we examine the global warming impact values of selected building materials, for example, we find that they are presented very differently from one source to the other. For instance, the values for linoleum according to Potting and Blok [34] are 4700 $\mathrm{gCO}_{2} \mathrm{eq} / \mathrm{m}^{2}$ vinyl while that from the work of Lippiatt is $478 \mathrm{gCO}_{2} \mathrm{eq} / \mathrm{f}^{2}$ [31]. Other global warming impact values for linoleum are $1000 \mathrm{gCO}_{2} \mathrm{eq} / \mathrm{kg}$ [32] and $930 \mathrm{gCO}_{2} \mathrm{eq} / \mathrm{f}^{2}$ [33]. Another example, the global warming impact values for parquet from different sources are: $12.7 \mathrm{kgCO} \mathrm{eq}_{2} / \mathrm{m}^{2}$ [34], $116 \mathrm{gCO}_{2} \mathrm{eq} / \mathrm{kg}$ [32], $341 \quad \mathrm{gCO}_{2} \mathrm{eq} / \mathrm{f}^{2}$ [33] and $-1.9 \mathrm{kgCO} 2 \mathrm{eq} / \mathrm{kg}$ (recycling of wastes included in the process) [35]. Other global impact values of selected building materials together with their measurement units and the functional units employed various studies are summarized in Table 2. From the above examples, it can be seen that there are differences in measurement and functional units, hence different numerical values. This makes it extremely difficult for designers in making comparisons and decisions. Consequently, there have been attempts to present impact values in other ways such as by using symbols or groupings in place of numbers for individual building materials. However, such approaches also have limitations as far as practitioners are concerned since detailed comparisons between materials cannot be made.

\section{Impact Values}

For comparison purpose, existing global warming values of selected materials were 'normalized' so that they are in the same units where possible. The results are shown in Table 3. It can be seen that the global warming impact values vary greatly even after they are converted to common units. For better clarity, the values are presented graphically in Figure 1.

The values for other impact categories from different studies are also different. Comparison among the results of assessing environmental impacts of ceramic tiles from our own research, Tikul and Srichandr [41] with those of Curran et al. [33], and Remmerswaal [35] is shown in Table 4. It can be seen that the impact values of each impact category from the three sources are quite different. This is despite the fact that all the three research work employed more or less the same study details. For example, the global warming impact value from Tikul and Srichandr [41] is $1203 \mathrm{kgCO}_{2} \mathrm{eq} / \mathrm{Mg}$ which is about three and six times greater than those from Curran et al.[33] and Remmerswaal [35] work, respectively.

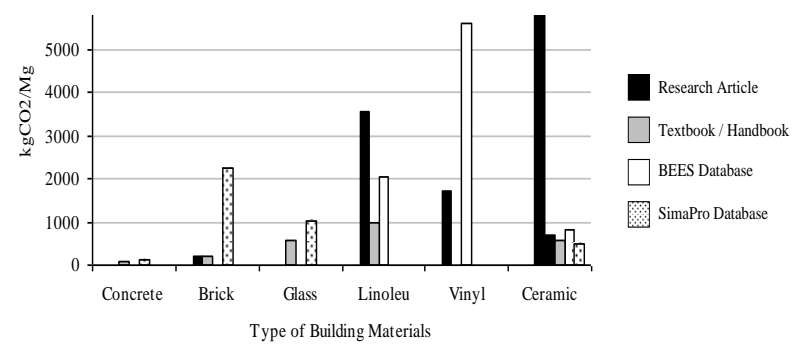

Figure 1. Comparisons of Global Warming Impact Values of Selected Building Materials 
Table 2. Global Warming Impact Values of Selected Building Materials

\begin{tabular}{|c|c|c|c|c|}
\hline \multirow{2}{*}{ Materials } & \multicolumn{4}{|c|}{ Sources } \\
\hline & Research Articles & Textbooks/Handbooks [32] & BEES Database [33] & SimaPro Database [35] \\
\hline Portland & & & $11090 \mathrm{gCO}_{2} \mathrm{eq} / \mathrm{f}^{3}(28 \mathrm{MPa})$ & $0.84 \mathrm{kgCO} 2 \mathrm{eq} / \mathrm{kg}$ \\
\hline Concrete & N/A & $65 \mathrm{gCO}_{2} \mathrm{eq} / \mathrm{kg}$ & N/A & $0.14 \mathrm{kgCO} 2 \mathrm{eq} / \mathrm{kg}$ \\
\hline Brick & $220.68 \mathrm{kgCO}_{2} \mathrm{eq} / \mathrm{Mg}[36]$ & $190 \mathrm{gCO}_{2} \mathrm{eq} / \mathrm{kg}$ & & $\begin{array}{l}2.25 \mathrm{kgCO}_{2} \mathrm{eq} / \mathrm{kg} \\
\text { (Refractory Brick) }\end{array}$ \\
\hline Glass & N/A & $569 \mathrm{gCO}_{2} \mathrm{eq} / \mathrm{kg}$ & N/A & $1.03 \mathrm{kgCO}_{2} \mathrm{eq} / \mathrm{kg}$ \\
\hline Linoleum & $\begin{array}{l}4700 \mathrm{gCO}_{2} \mathrm{eq} / \mathrm{m}^{2}[34] \\
4780 \mathrm{gCO}_{2} \mathrm{eq} / \mathrm{m}^{2}[31] \\
1600 \mathrm{gCO}_{2} \mathrm{eq} / \mathrm{m}^{2}[37]\end{array}$ & $1000 \mathrm{gCO}_{2} \mathrm{eq} / \mathrm{kg}$ & $930 \mathrm{gCO} 2 \mathrm{eq} / \mathrm{f}^{2}$ & N/A \\
\hline Vinyl & $\begin{array}{c}9500 \mathrm{gCO}_{2} \mathrm{eq} / \mathrm{m}^{2}[34] \\
4206 \mathrm{gCO}_{2} \mathrm{eq} / \mathrm{m}^{2}[37] \\
1409 \mathrm{gCO}_{2} \mathrm{eq}^{2} / \mathrm{f}^{2}[31]\end{array}$ & N/A & $1060 \mathrm{gCO}_{2} \mathrm{eq} / \mathrm{f}^{2}$ & N/A \\
\hline Marble & 7.10E-13 Pt/m² [38] & $1210 \mathrm{gCO}_{2} \mathrm{eq} / \mathrm{kg}$ & $2687 \mathrm{gCO}_{2} \mathrm{eq} / \mathrm{f}^{2}$ & N/A \\
\hline Ceramic tile & 1.93E-12 Pt/m² [38] & $571 \mathrm{gCO}_{2} \mathrm{eq} / \mathrm{kg}$ & $1994 \mathrm{gCO}_{2} \mathrm{eq} / \mathrm{f}^{2}$ & $0.69 \mathrm{kgCO}_{2} \mathrm{eq} / \mathrm{kg}$ \\
\hline Parquet & $12.7 \mathrm{kgCO}_{2} \mathrm{eq} / \mathrm{m}^{2}[34]$ & $116 \mathrm{gCO}_{2} \mathrm{eq} / \mathrm{kg}$ & $341 \mathrm{gCO}_{2} \mathrm{eq} / \mathrm{f}^{2}$ & $-1.9 \mathrm{kgCO}_{2} \mathrm{eq} / \mathrm{kg}$ \\
\hline
\end{tabular}

Table 3. Global Warming Values of Selected Materials $\left(\mathrm{kgCO}_{2} \mathrm{eq} / \mathrm{Mg}\right)$

\begin{tabular}{lcccc}
\hline \multirow{2}{*}{ Materials } & \multicolumn{3}{c}{ Sources } & \\
\cline { 2 - 5 } & Research Articles & Textbooks/Handbooks [32] & BEES Database [33] & SimaPro Database [35] \\
\hline Concrete & N/A & 65 & N/A & 140 \\
\hline Brick & $220.68[36]$ & 190 & & 2250 \\
& N/A & 569 & N/A & (Refractory Brick) \\
\hline Glass & 3563 & 1000 & 2043 & N/A \\
\hline Linoleum & $1729[31]$ & N/A & 5588 & N/A \\
\hline Vinyl & $5.36[27]$ & 571 & 806 & 494 \\
Ceramic tile & $\begin{array}{r}16200[39] \\
706[40]\end{array}$ & & & \\
\hline
\end{tabular}

Table 4. Environmental Impact Values per $1 \mathrm{Mg}$ of Ceramic Tile

\begin{tabular}{lcccc}
\hline $\begin{array}{c}\text { Environmental } \\
\text { Impact }\end{array}$ & Unit (kg) & $\begin{array}{c}\text { Tikul and } \\
\text { Srichandr } \\
{[41]}\end{array}$ & $\begin{array}{c}\text { Curran } \\
\text { et al. } \\
{[33]}\end{array}$ & $\begin{array}{c}\text { Remmers- } \\
\text { waal } \\
{[35]}\end{array}$ \\
\hline Global warming & $\mathrm{CO}_{2}$ eq. & 1,203 & 340.8 & 208.8 \\
Acidification & $\mathrm{H}^{+}$eq. & 103.2 & 129.6 & 47.2 \\
Euthophication & $\mathrm{NO}_{3}$ eq. & 0.058 & 0.04 & 0.028 \\
Ozone Depletion & $\mathrm{CFC}^{2}$-11eq. & $9.8 \mathrm{E}-6$ & $\mathrm{~N} / \mathrm{A}$ & $8.4 \mathrm{E}-9$ \\
Ecotoxicity & 2,4-Deq. & 80.4 & 1.96 & 0.13 \\
Smog & $\mathrm{NO}_{\text {xeq. }}$ & 1.04 & 0.68 & 0.64 \\
\hline
\end{tabular}

The results show that existing environmental impact data of building materials from different sources differ markedly. From the designers' point of view, this is perplexing and it is almost impossible to use the data for selecting environmentally-benign materials. There are many possible causes that give rise to such differences including transport distance of raw materials, production technologies and manufacturing practice, pollution control measures etc. If the data can be somehow presented in the forms that are more designer-friendly, they would certainly be used more widely in real life applications.

\section{Scope of Studies}

Careful examination of a number of studies on assessing environmental impacts of building materials reveals that different studies cover different scopes i.e. cover different phases of the life cycle of materials. None of the studies covered the full life cycle, from cradle to grave. The scope of studies of selected research work on ceramic tiles is shown in Figure 2. Differences in scope of studies are one of the reasons that result in differences in environmental impact values of the same building materials.

The results show that existing environmental impact data of building materials from different sources differ markedly. From the designers' point of view, this is perplexing and it is almost impossible to use the data for selecting environmentally-benign materials. There are many possible causes that give rise to such differences including transport distance of raw materials, production technologies and manufacturing practice, pollution control measures etc. If the data can be somehow presented in the forms that are more designer-friendly, they would certainly be used more widely in real life applications.

\section{Scope of Studies}

Careful examination of a number of studies on assessing environmental impacts of building materials reveals that different studies cover different scopes i.e. cover different phases of the life cycle of materials. None of the studies covered the full life cycle, from cradle to grave. The scope of studies of selected research work on ceramic tiles is shown in 


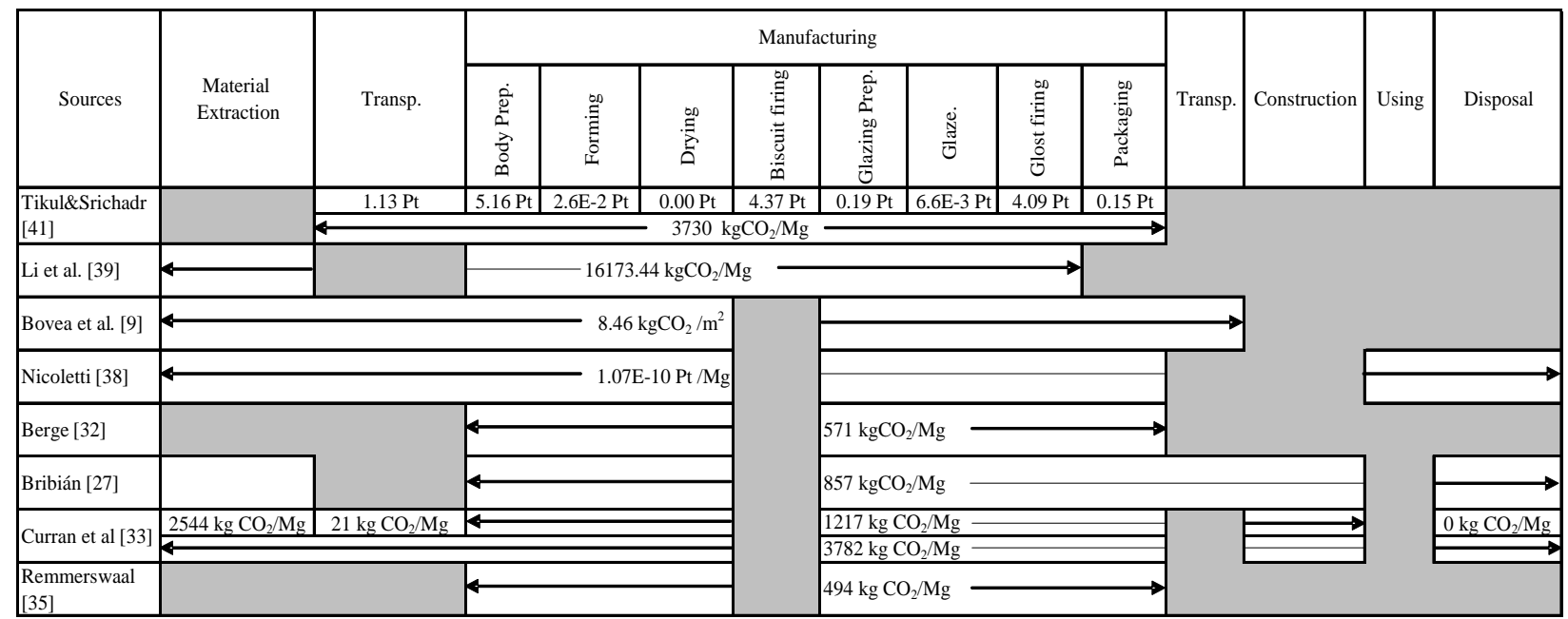

Figure 2. Comparisons of the Scope of LCA Studies from Various Sources

Figure 2. Differences in scope of studies are one of the reasons that result in differences in environmental impact values of the same building materials.

\section{Sources of Data Variation}

Examining and analyzing the information in the literature and that from Tikul and Srichandr [41], it is found that there are numerous possible causes that lead to different values of environmental impact data. The author has identified three major categories of sources that lead to discrepancies in impact values of building materials.

The first category is production processes and technologies employed. Different processes and technologies result in different impact values. This is evident in Tikul and Srichandr's work [41]. The author assessed environmental impacts of ceramic tiles produced by two Thai firms who employed different production processes and technologies and found that the values are very different. Examining the work of others also reveal the same results [28, 42-44].

The next category is the study details. These include scope of study, definition of functional units, methods of measurement and data collection, methods of inventory analysis and assessment. If such study details are different, the resulting impact values will be invariably different. Examining such details in the literature $[28,29,43,44]$, it is found that they differ considerably from one study to another. In fact, there are no two studies which are exactly the same. Statistical analysis of data were performed in only a limited number of studies and often neglected, particularly in earlier ones. It is therefore not really surprising that the values from different studies are different.
The last category is a temporal one, the time factor that leads to differences in impact values. It is observed that older values are different from newer ones. It is quite probable that the temporal effects are related to the first two categories. Modern manufacturing practices and technologies could lead to different impact values from those obtained in the past [28]. More recent investigations would employ different methodologies in conducting research and different methods of data analysis thus resulting in different values. Better knowledge and understanding about the subject matter of those involved could also contribute to difference in impact values. Other things being equal, one might assume that the newer values are more accurate than older ones.

\section{Designers' Perspectives}

For practicing architects and engineers, the nature of existing data on environmental impacts of building materials as presented above is overwhelming and perplexing. The interviews with practicing architects in Thailand reveal clearly that they are well aware of deteriorating environmental problems and are willing to incorporate environmental consideration in building design. Implementation is extremely difficult in practice, however. Key obstacles are lack of relevant and reliable data that can be readily used and lack of user-friendly tools for the implementation. Selecting environmental-friendly materials is particularly problematic in this regard. Being laypersons as far as environmental impacts of materials are concerned, they can hardly know which data are appropriate, which are reliable, which are relevant, and which should be selected. This is unfortunate for they are the ones who actually use the data in practice, who could actually make a difference and make the hard-earned research data truly beneficial and effective. 
Designers evaluate candidate materials in various ways before reaching final decisions [21,23]. They may base their decisions, for example, on a weighted performance indices which are obtained from giving 'weights' to key performance requirements of individual candidate materials, multiply them, and sum them up. The material with the highest index is selected $[14,16]$. Performance requirements of materials may include things like load carrying capacity, strength, weight, thermal insulation, cost, and so on. Others may employ simple calculations and their experience in selecting materials. Still others may employ sophisticated materials selection softwares based on complex fuzzy mathematics with large material database [45-47]. A number of materials selection models employing various approaches have been developed in recent years [48,49]. In all cases, the input materials data have to be clear, specific, and reliable, if the outputs, hence subsequent decisions, are to be truly meaningful and beneficial. If the input data are uncertain or unreliable, the outputs, no matter how elaborate the selection models, cannot possibly be reliable. Making decisions without definite and reliable data are extremely difficult if not impossible. One has no choice but resort to the 'old way of doing things' using intuition and experience as the bases for making decisions.

Ideally, designers would prefer a single value, or a narrow range of values, for environmental impact data of a material rather like mechanical and other properties. It would then be quite easy to include environmental impacts in materials selection equations. This is impossible in the case of environmental impact values, however, as the impacts are generated throughout the life cycle of materials. Life cycle assessment approach must be, however, used in order that the results represent the impacts accurately, thus making the data truly reliable. Variables in various phases of the life cycle of materials; production technology and transportation distance, for example, could affect the final results [27,28] considerably as are evident in existing data presented in Figure 2.

\section{Limitations of the Life Cycle Approach}

Although the life cycle approach to environmental impact assessment is deservedly well accepted internationally, there are some limitations. Firstly, implementing the approach in practice is not an easy task. For the full life cycle assessment of a building material, ceramic tiles for example, one needs to cover the extraction and production of all the raw materials required to produce the tiles, the transportation of all raw materials to production plants, all production stages, packaging, transportation of finished products, construction, maintenance, and end-of-life issues. Individual phases might involve a number of factors that need to be taken into account in order to assess the impact accurately. Most studies therefore limit the scope of the investigations within certain phases so that they are manageable. The final impact values are therefore not really those of the whole life cycle but partial life cycle of the materials. Changes in the scope of study inevitably lead to changes in environmental impact values. This is one of the reasons for the differences in impact values in the literatures.

The second limitation is related to the uniqueness of individual studies. By its very nature, each study that employs the life cycle approach is a case study. The results of any study are, strictly speaking, only applicable to that particular case. Generalization of the results is extremely difficult or impossible. In the production of a certain building material, different firms employing different manufacturing practices and are located at different distances from raw materials sources, are bound to generate different values of environmental impacts [28-30].

It is clear from the above discussion that obtaining accurate environmental impact data of building materials is very difficult. Each data set from individual study is derived from a very specific set of conditions unique for that study. Users of the data in different settings are bound to generate errors or uncertainties. Tremendous progress has been made regarding environmental impact assessment of building materials but a lot of work still needs to be done before designers could readily use environmental impact data in materials selection in real life practices.

\section{Possible Solutions}

How can the environmental impact data of building materials be made more user-friendly? How can one improve external validity of research data so that they could be more widely and reliably used? These are the key questions that must be addressed if environmental impacts of building materials are to be seriously considered and included in materials selection equations by practicing architects and engineers.

We believe that the life cycle approach is necessary for determining accurate environmental impact values of building materials. However, obtaining the data that cover the full life cycle of materials and the data that are applicable to a wider range of situations are difficult as discussed earlier. The author proposes that the full life cycle of materials be broken down to appropriate 'phases' and the impacts resulting from individual phases are then deter- 
mined in terms of key variables contributing to the impacts in that particular phase. The overall impacts of the materials are the sums of the impacts of individual phases throughout the life cycle.

In the case of ceramic tiles, for example, the full life cycle may be divided into 9 phases: extraction and production of all raw materials, transportation of all raw materials from their sources to manufacturing plants, materials preparation, forming, firing, packaging, transportation of finished products to construction sites, construction, maintenance in the use phase, and end-of-life phase. Environmental impacts of individual phases are then determined in terms of key variables in that phase. For example, in the transportation-of-finished-products phase, the key variables would be the distances between manufacturing plants and construction sites, and the means of transportation and the types of transporttation equipment employed. Suppose we know, for instance, that the distance is $100 \mathrm{~km}$ and 28 -ton diesel trucks are used for the transportation, we can calculate the amount of environmental impact due to this transportation-of-finished-products phase in this particular situation. If the distance and the means of transportation are different, the impact values will be different, of course.

Impact values of other phases can be determined in a similar way. The challenge is to identify key variables affecting the impacts and the establishment of functional relationships between the impacts and the variables for each phase. Summing up all the impacts values from all the phases would yield the total impacts of the material throughout its life cycle.

One advantage of this approach to assessing environmental impacts of materials is that the results can be used in a wide range of situations. Once the functional relationship between the impact value and the key variables for each phase is established, the value can be determined for that phase in other situations, thus increasing the external validity of the results. This is in contrast with current practice where the impacts of all the phases within the scope of study are evaluated collectively making the results very specific to that particular study. Using the results from that study in other situations is therefore invalid.

Another advantage is that the full life cycle impacts of materials can be realistically achieved. Once the impacts of individual phases are determined, one can simply add the values to get the total life cycle impact. Individual phases may be investigated by different researchers or at different times and the results can be used by others or at later dates. The tasks are more manageable compared with current practice where the determinations of the impacts of all the phases are attempted in one go which is an enormous task. Researchers therefore have to limit the scope of studies to make the task manageable as mentioned earlier. The results of such limited-scopestudies do not reflect the full life cycle impact values as they are determined from limited scope of the life cycle.

The proposed approach for environmental impact data acquisition is analogous to the modular approach to product design. Individual phases in the life cycle of materials correspond to individual 'modules' of products. Modules may be developed by different parties and can be later assembled to make complete products. Current practice is analogous to integrated design approach where every part must be designed for specific products. Improvements of integrated products are difficult compared with improving modular products.

\section{Conclusion}

With increasingly deteriorating environmental problems, it is imperative that the products of the future, including buildings, designed in such a way that they are more environmental-friendly. Buildings consume vast amount of materials which generate huge environmental impacts. Proper selection of building materials would help improve environmental friendliness of buildings and consequently mitigating environment problems.

Existing environmental impact data of any particular building material differ considerably from one source to another. It is difficult for designers in evaluating and selecting building materials that are friendly to the environment. Environmental considerations are often neglected in the material selection stage of building design. Improvements on existing data are necessary if the data are to be extensively used in practice.

An alternative approach for data acquisition and presentation is proposed. The full life cycle of building materials is divided into several phases. The environmental impact of each phase is determined in terms of key variables affecting the impacts, i.e. establishing functional relationships between the impacts and key variables in that particular phase. The total impact value is the sum of the impacts of all the phases. This approach would make the determination of the full life cycle value feasible as well as increasing external validity of research results. The final outcome of the approach would be more reliable and more user-friendly environmental impact values. 


\section{References}

1. Ortiz, O., Castells, F., and Sonnemann, G., Important Issues in LCA and Ecodesign within the Building Sector for Developing Countries, Proceedings of the International Conference on Life Cycle Assessment CILCA 2007, Sao Paulo, 2007.

2. Yeang, K., Ecodesign: A Manual for Ecological Design, John Wiley \& Sons, London 2008.

3. Miettinen, P. and Hamalainen, P.R., How to Benefit from Decision Analysis in Environmental Life Cycle Assessment (LCA), European Journal of Operational Research, 102(3), 1997, pp. 279-294.

4. Fadamiro, J.A. and Bobadoye, S., Managing the Building Design Process for Sustainability and Improved Quality, Civil Engineering Dimension, 8(1), 2006, pp. 1-7.

5. Rydh, J.C. and Sun, M., Life Cycle Inventory Data for Materials Grouped According to Environmental and Material Properties, Journal of Cleaner Production, 13(1), 2005, pp. 12581268.

6. Lippiatt, C.B., Building for Environmental and Economic Sustainability Technical Manual and User Guide, Building and Fire Research Laboratory, National Institute of Standards and Technology Gaithersburg, MD, 2007.

7. Spiegel, R. and Meadows, D., Green Building Materials: A Guide to Product Selection and Specification, John Wiley \& Sons, NY, 1999.

8. Tikul, D. and Srichandr, P., Status of Ecodesign in Architecture in Thailand, In: Proceedings of the International Conference on Life Cycle Management LCM 2007, Switzerland, 2007.

9. Bovea, M.D. and Gallardo, A., The Influence of Impact Assessment Methods on Materials Selection for Eco-design, Materials and Design, 27(3), 2006, pp. 209-215.

10. Cao, H., Liu, F., Li, C. and Liu, C., An Integrated Method for Product Material Selection Considering Environmental Factors and A Case Study, Materials Science Forum, China, 2006, pp. 1032-1035.

11. Chan, J.W.K. and Tong, T.K.L., Multi-Criteria Material Selections and End-of-Life Product Strategy: Grey Relational Analysis Approach, Materials and Design, 28, 2007, pp. 539-546.

12. Huang, H., Liu, G., Liu, Z., and Pan, J., Multiobjective decision-making of materials selection in green design, Journal of Mechanical Engineering, 42, 2006, pp, 131-136.
13. Ljungberg, L.Y. and Edwards, K.L., Design, Materials Selection and Marketing of Successful Products, Materials and Design, 24, 2003, pp. 519-529.

14. Farag, M.M. and El-Magd, E., An Integrated Approach to Product Design, Materials Selection and Cost Estimation, Materials and Design, 13, 1992, pp. 323-327.

15. Mattias, L., Engineering Designers' Requirement Methods and Tools, KTH Industrial Engineering and Management, Stockholm, Sweden, 2005.

16. Ashby, M.F., Brechet, Y.J.M., Cebon, D. and Salvo, L., Selection Strategies for Materials and Processes, Materials and Design, 25, 2004, pp. 51-67.

17. Liao, T.W., A Fuzzy Multicriteria DecisionMaking Method for Material Selection, Journal of Manufacturing Systems, 15, 1996, pp. 1-12.

18. Rao, R.V. and Davim, J.P., A Decision-Making Framework Model for Material Selection Using a Combined Multiple Attribute Decision-Making Method, International Journal of Advanced Manufacturing Technology, 35, 2008, pp. 751760.

19. Rao, R.V., A Material Selection Model Using Graph Theory and Matrix Approach, Materials Science and Engineering, 431, 2006, pp. 248255.

20. Rao, R.V., A Decision Making Methodology for Material Selection Using an Improved Compromise Ranking Method, Materials and Design, 29, 2008, 1949-1954.

21. Karana, E., Hekkert, P., and Kandachar, P., Material Considerations in Product Design: A Survey on Crucial Material Aspects Used by Product Designers, Materials and Design, 29, 2008, pp. 1081-1089.

22. Pedgley, O.F., Influence of Stakeholders on Industrial Design Materials and Manufacturing Selection, International Journal of Design, 3, 2009, pp. 1-15.

23. Van, K., Kandachar, P.V., and Stappers, P.J., Activities in Selecting Materials by Product Designers, Proceedings of the International Conference on Advanced Design and Manufacture, Harbin, China, 2006.

24. Ljungberg, L.Y., Materials Selection and Design for Development of Sustainable Products, Materials and Design, 28, 2007, 466-479.

25. Zhou, C.C., Yin, G.F. and Hu, X.B., MultiObjective Optimization of Material Selection for Sustainable Products: Artificial Neural Networks and Genetic Algorithm Approach, Materials and Design, 30, 2009, pp, 1209-1215. 
26. Bretz, R., SETAC LCA Workgroup: Data Availability and Data Quality, CIBA Specialty Chemicals Inc., Consumer Care Division, Switzerland, 1998.

27. Bribián, Z.I., Life Cycle Assessment in Buildings: State-of-the-Art and Simplified LCA Methodology as a Complement for Building Certification, Building and Environment, 44(12), 2009.

28. Huijbregts, M.A.J., Uncertainty and Variability in Environmental Life-Cycle Assessment. $\mathrm{PhD}$ Thesis, Universiteit van Amsterdam, Amsterdam, 2001.

29. Grant, T., Inclusion of Uncertainty in LCA, Centre for Design at RMIT University, Melbourne, 2009.

30. Heijungs, R. and Huijbregts, A.J.M., A Review of Approaches to Treat Uncertainty in LCA, International Environmental Modeling and Software Society, 2004.

31. Lipiatt, C.B., Selecting Cost-Effective Green Building Products: BEES Approach, Journal of Construction Engineering and Management, November-December, 1999.

32. Berge, B., The Ecology of Building Materials, Great Britain: Architectural Press, 2001.

33. Curran, M.A., Overly, J.G., Hofstetter, P., Muller, R., and Lippiatt, C.B., Building for Environmental and Economic Sustainability Peer Review Report, National Institute of Standards and Technology (NIST), USA, 2002.

34. Potting, J. and Blok, K., Life Cycle Assessment of Four Types of Floor Covering, The Journal of Cleaner Production, 3(4), 1995, pp. 201-213.

35. Remmerswaal, H., IDEMAT 2001 Project: Engineering Materials (Metals, Alloys, Plastics, Wood), Energy, Transport, Faculty of Industrial Design Engineering, Delft Technical University, Netherlands, 2001.

36. Koroneos, C. and Dompros, A., Environmental Assessment of Brick Production in Greece, Building and Environment, 42, 2007, pp. 21142123.

37. Jonsson, A., Tillman, A.M., and Svensson, T., Life Cycle Assessment of Flooring Materials: Case Study, Building and Environment, 32(3), 1997, pp. 245-255.
38. Nicoletti, G.M., Comparative Life Cycle Assessment of Flooring Materials: Ceramic Versus Marble tiles, Journal of Cleaner Production, 10, 2002, pp. 283-296.

39. Li, X., Wang, Z. and Nie Z., Life Cycle Assessment of Chinese Typical Ceramic Tile, Beijing University of Technology, China, 2008.

40. Goldoni, S. and Bonoli, A., A Case Study About LCA of Ceramic Sector: Application of Life Cycle Analysis Results to the Environment Management System Adopted by the Enterprise, University of Bologna, Italy, 2006.

41. Tikul, D. and Srichandr, P., Comparative Global Warming of Ceramic Tile Production in SMEs in Thailand, Office of the National Research Council of Thailand, 2007.

42. Funtowicz, S.O., Ravetz, J.R., Uncertainty and Quality in Science for Policy, Dordrecht: Kluwer Academic Publishers, 1990.

43. Bretz, R., SETAC LCA Workgroup: Data Availability and Data Quality, CIBA Specialty Chemicals Inc., Consumer Care Division, Switzerland, 1998.

44. Bevington, P.R. and Robinson, D.K., Data Reduction and Error Analysis for the Physical Sciences, $2^{\text {nd }}$ ed, McGraw-Hill, NY, 1992.

45. Balakrishna, A., Rao, D.N., Srinivas, J., and Satish, P., Computer Aided Material Selection Processes in Concurrent Engineering Using Neural Networks, Journal of the Institute of Engineering (India), Mech Eng Div, 88, 2007, pp. 20-23.

46. Cebon, D. and Ashby, M., Data Systems for Optimal Material Selection, Advanced Materials Process, 161, 2003, pp. 51-54.

47. Jalham, I.S., Computer-Aided Quality Function Deployment Method for Material Selection, International Journal of Computer Applications in Technology, 26, 2006, pp. 190-196.

48. Shanian, A. and Savadogo, O., A Methodological Concept for Material Selection of Highly Sensitive Components based on Multiple Criteria Decision Analysis, Expert Systems with Applications, 36, 2009, pp. 1362-1370.

49. Sharif Ullah, A.M.M. and Harib, K.H., An Intelligent Method for Selecting Optimal Materials and its Application, Advanced Engineering Informatics, 22, 2008, pp. 473-483. 